\section{Building research infrastructure across a health service}

François Lamontagne and colleagues very usefully raise important questions about how health research in Canada might be better organized to enhance its impact on clinical practice. ${ }^{1}$ Given the achievements of health research in the United Kingdom during the coronavirus disease 2019 pandemic, the authors rightly laud the Clinical Research Network infrastructure for facilitating research that leads to key advances.

There are additional reasons for building research infrastructure widely across a health service. In England, National Health Service (NHS) hospitals in the cancer research network that participated in colorectal cancer trials had lower mortality rates from colorectal cancer than other hospitals, after adjusting for case mix and hospital-level variables. This trend was not restricted to academic centres or large hospitals, but there was a dose effect. ${ }^{2}$ The effect of research engagement on health care performance, though, is not unique to England or to research networks. A review of global literature on research engagement by health care providers found that North America provided the majority of studies reporting improved health care performance associated with clinicians or health care organizations that were active in research. ${ }^{3}$

That leads to the observation that perhaps the most important aspect of Dame Sally Davies' formation of the English National Institute for Health Research (NIHR) was not the adoption of any one specific element, but rather the creation of the overall system. This achievement was recognized in a recent review by the
World Health Organization (WHO) that identified the NIHR as a world leader in implementing a comprehensive and coherent strategy to undertake the 4 main research system functions of governance, funding, building capacity and production and use of evidence. ${ }^{4}$

For example, building research networks across the NHS partly balanced the emphasis on funding a small number of Biomedical Research Centres (BRCs) to host leading medical academics who would spearhead research and translation. Many major scientific advances have come from BRCs. The University of Oxford's BRC supports the RECOVERY trial, led by the university and involving investigators and clinical centres across the NIHR's Clinical Research Network. BRCs helped the NIHR secure buy-in from leading medical academics, essential for the system to work in the context of some unease about focusing research agendas to meet NHS needs.

Lamontagne and colleagues identified challenges and progress in Canada, including clinical networks in Alberta. The WHO review provided more evidence of progress in Canada. First, the role of the Alberta networks in enhancing the translation and impact of research has been analyzed using the WHO's systems approach. ${ }^{5}$ The WHO review also noted the pioneering comprehensive health research strategy developed in British Columbia through extensive stakeholder engagement, and the important role of McMaster University in evidence synthesis and translation (which has crucially continued during the pandemic).

Finally, it is worth recalling that a key influence behind the developments that led to the NIHR was the belief that clinical practice should be driven by evidence. This belief, of course, goes back to McMaster and Dr. David Sackett (who then went to the University of Oxford).

- Cite as: CMAJ 2021 March 1;193:E315. doi: 10.1503/cmaj. 77958

\section{Stephen R. Hanney PhD}

Professor emeritus, Brunel University London, Uxbridge, UK

\section{References}

1. Lamontagne F, Rowan KM, Guyatt G. Integrating research into clinical practice: challenges and solutions for Canada. CMAJ 2021;193:E127-31.

2. Downing A, Morris EJA, Corrigan N, et al. High hospital research participation and improved colorectal cancer survival outcomes: a populationbased study. Gut 2017;66:89-96.

3. Boaz A, Hanney S, Jones T, et al. Does the engagement of clinicians and organisations in research improve healthcare performance: a three-stage review. BMJ Open 2015;5:e009415.

4. Hanney S, Kanya L, Pokhrel S, et al. What is the evidence on policies, interventions and tools for establishing and/or strengthening national health research systems and their effectiveness? [Internet] Copenhagen: WHO Regional Office for Europe; 2020. (Health Evidence Network Synthesis Report, No. 69.) SUMMARY. Available: www. ncbi.nlm.nih.gov/books/NBK558507/ (accessed 2020 Dec. 21)

5. Hanney SR, Ovseiko PV, Graham KER, et al. A systems approach for optimizing implementation to impact: meeting report and proceedings of the 2019 In the Trenches: Implementation to Impact International Summit. BMC Proc 2020;14:10.

\section{Competing interests: None declared.}

Content licence: This is an Open Access article distributed in accordance with the terms of the Creative Commons Attribution (CC BY-NC-ND 4.0) licence, which permits use, distribution and reproduction in any medium, provided that the original publication is properly cited, the use is noncommercial (i.e., research or educational use), and no modifications or adaptations are made. See: https://creativecommons.org/ licenses/by-nc-nd/4.0/ 